\title{
ANALISIS PENERIMAAN DAN PENGGUNAAN MEDIA PEMBELAJARAN AUGMENTED REALITY DENGAN MENGGUNAKAN MODEL UTAUT-2 (Studi Kasus : SMP dan SMA MUTIARA BUNDA BANDUNG)
}

\author{
Zatin Niqotaini \\ Program Studi Sistem Informasi, Universitas Informatika dan Bisnis Indonesia \\ J1. Soekarno Hatta No. 643 Bandung \\ zatinniqotaini@unibi.ac.id
}

\begin{abstract}
ABSTRAK
Penerimaan penggunaan media pembelajaran Augmented Reality perlu diperhatikan untuk mengetahui berhasil tidaknya dalam penerapannya di SMP dan SMA Mutiara Bunda Model UTAUT-2 (Venkantesh, $d k k$, 2012) menunjukkan bahwa behavioral intention dan use behavior dipengaruhi performance expectancy, effort expectancy, social influence, facilitating conditions, hedonic motivation, dan price value, serta self management of learning yang dimoderasi gender, age, dan experience. Hasil penelitian menunjukkan penerimaan penggunaan Augmented Reality SMP dan SMA Mutiara Bunda dipengaruhi variabel Performance Expectancy, Hedonic Motivation, dan Habit.
\end{abstract}

Kata Kunci : Penerimaan Teknologi, Media Pembelajaran, Augmented Reality, UTAUT-2, Structural Equation Model.

\section{PENDAHULUAN}

Perkembangan teknologi informasi dan komunikasi yang begitu pesat telah mempengaruhi berbagai bidang kehidupan. Berbagai informasi kini dapat disampaikan dengan banyak melibatkan bidang multimedia. Teknologi di bidang multimedia yang sedang berkembang adalah Augmented Reality.

Dalam menyelenggarakan layanan pendidikannya, SMP dan SMA Mutiara Bunda mengembangkan teknologi informasi multimedia AR sebagai media pembelajaran. Diharapkan penyampaian materi dalam mata pelajaran yang membutuhkan daya visual akan tersampaikan dengan baik. Namun penerimaan penggunaan media pembelajaran Augmented Reality perlu diperhatikan untuk mengetahui berhasil atau tidak dalam penerapannya.

UTAUT-2 merupakan sebuah model untuk menjelaskan perilaku pengguna terhadap teknologi informasi (Venkantesh, dkk, 2012)[1]. Model UTAUT-2 menunjukkan bahwa niat untuk berperilaku (behavioral intention) dan perilaku untuk menggunakan suatu teknologi (use behavior) dipengaruhi oleh ekspektasi kinerja (performance expectancy), ekspektasi usaha (effort expectancy), faktor pengaruh sosial (social influence), kondisi fasilitas pendukung (facilitating conditions), motivasi hedonis (hedonic motivation), dan harga (price value). Faktor-Faktor tersebut dimoderasi oleh faktor jenis kelamin (gender), usia (age), dan pengalaman (experience).

Tujuan penelitian ini adalah mengetahui faktor apa saja yang mempengaruhi/ mendorong peningkatan penerimaan penggunaan media pembelajaran $\mathrm{AR}$, mengetahui besar pengaruh masing-masing faktor dalam penerimaan dan penggunaan media pembelajaran AR, mengetahui rekomendasi-rekomendasi untuk mengoptimalkan penerimaan dan penggunaan media pembelajaran AR.

[2] Penelitian Ilana de A. Souza-Concilio (2013:4) yang berjudul The Development of Augmented Reality Systems in Informatics Higher Education terhadap para pengguna aplikasi (students) diantaranya aplikasi berteknologi AR, menunjukan bahwa $82 \%$ pengguna aplikasi menggunakan untuk kepentingan games dan hiburan, sementara $18 \%$ lainnya digunakan untuk kepentingan pendidikan. Melalui data penelitian ini, ditunjukan bahwa terdapat fenomena di mana teknologi informasi lebih banyak dimanfaatkan untuk games dan hiburan dibandingkan untuk Pendidikan. 


\section{METODE PENELITIAN}

Penelitian menurut Sugiyono [3] merupakan penelitian kuantitatif yang dilakukan terhadap sampel, teknik pengambilan sampel dilakukan secara random proporsional, pengumpulan data dilakukan melalui instrumen, analisis data bersifat kuantittif statistik deskriptif untuk menguji hipotesis yang telah ditetapkan dan untuk menunjukkan hubungan antar variabel.

Jumlah kuesioner dengan data yang dapat diolah adalah sebanyak 298 eksemplar atau 49\% dari populasi di SMP dan SMA Mutiara Bunda. Pengujian model dilakukan dengan menggunakan model perluasan model UTAUT2 dengan dengan menambahkan konstruk Manajemen Pembelajaran Diri (Self Management of Learning) dalam penerimaan dan penggunaan media pembelajaran AR.

1. Identifikasi Minat Penelitian dilanjutkan pemilihan topik.

2. Pengumpulan data awal.

Teknik pengumpulan data awal di lakukan dengan wawancara dengan pihak SMP dan SMA Mutiara Bunda.

3. Perumusan Masalah

Keadaan saat ini yang menjadi permasalahan diperoleh dari hasil wawancara dan beberapa fakta-fakta yang ada. Setelah membandingkan antara ekspektasi dan kenyataan saat ini, diketahuilah gap yang kemudian dirumuskan masalahnya oleh peneliti.

4. Tinjauan Pustaka

Melakukan studi literatur yang lebih intensif mengenai teori, penelitianpenelitian sebelumnya dan metodologi yang relevan dengan topik pembahasan penelitian ini.

5. Pengembangan Kerangka Pemikiran

Pengembangan kerangka pemikiran dilakukan dengan cara membandingkan dan mencari persamaan dengan penelitian terdahulu yang berkaitan dengan tingkat penerimaan sistem informasi.

6. Perumusan Hipotesis

Perumusan hipotesis dilakukan dengan acuan variabel-variabel yang dibentuk pada kerangka pemikiran.

7. Pengumpulan data

Instrumen yang akan digunakan pada tahap pengumpulan data adalah dengan menggunakan kuesioner.

8. Uji Outer Model

Uji Outer Model meliputi uji validitas yaitu uji validitas konvergen dan uji validitas diskriminan selain itu juga uji reliabilitas dapat dilihat dari nilai Cronbach's Alpha dan nilai Composite Reliability.

9. Uji Inner Model

Uji Inner Model dengan pengujian struktural meliputi 2 bagian utama, yaitu:

a. Menguji keseluruhan model (overall model fit) dari struktural model

b. Menguji struktural estimasi yakni hubungan diantara konstruk yang ada

10. Uji Efek Moderasi

Setelah didapatkan model yang umum, maka akan dilakukan pengujian terhadap variabel-variabel moderasi yang ada di penelitian ini.

11. Model Penelitian Akhir

Bagian hasil dan pembahasan ini akan mengulas bagaimana model penerimaan yang dihasilkan dari analisa AMOS dan dibandingkan dengan hipotesis penelitian yang sudah ditentukan sebelumnya. Dari sini kemudian diketahui hipotesishipotesis yang diterima dan ditolak oleh analisis AMOS.

12. Kesimpulan dan Saran

Menyimpulkan seluruh penelitian yang sudah dilakukan oleh peneliti serta memberikan saran-saran berkaitan dengan dampak penelitian yang sudah dilakukan. 


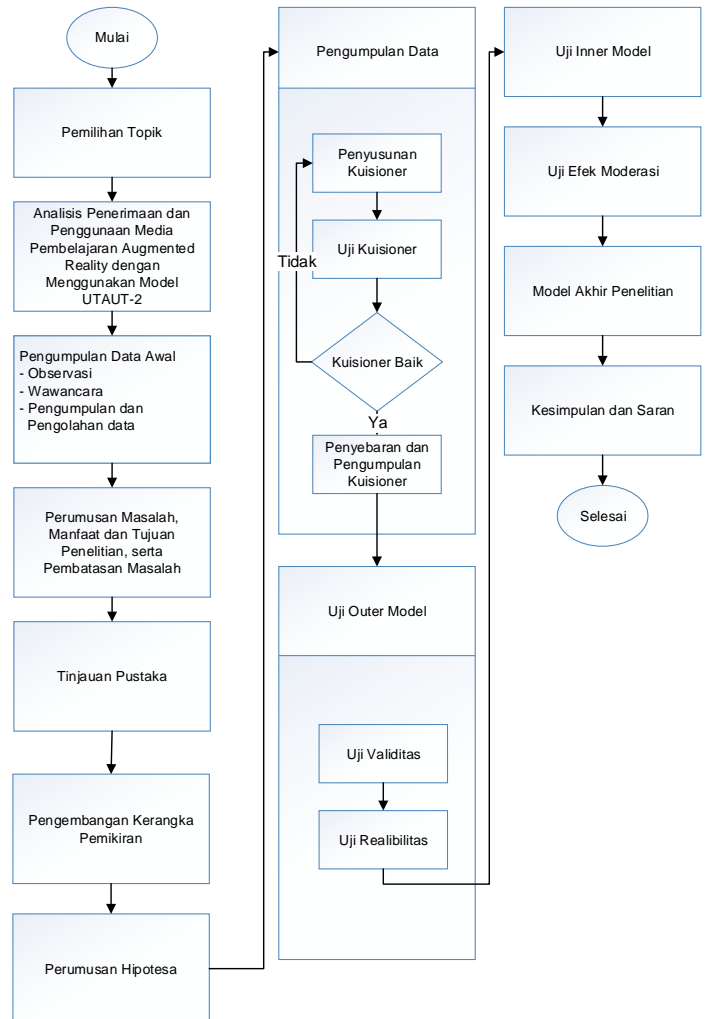

Gambar 1. Bagan Tahapan Penelitian

\section{HASIL DAN PEMBAHASAN}

\section{A. Path Diagram}

Setelah penyusunan model SEM dan juga variabel beserta indikator-indikatornya, tahapan selanjutnya adalah pembuatan path diagram. Path diagram yang disusun berdasarkan model yang telah dibuat tersebut dapat dilihat pada gambar 1.

\section{B. Uji Validitas}

Pengujian validitas mengukur sampai seberapa jauh ukuran indikator mampu merefleksikan konstruk laten teoritisnya. Untuk mengukur validitas konstruk dapat dilihat dari loading factor. Pada penelitian ini dilakukan analisa model CFA (Confirmatory Factor Analysis). rangkuman hasil uji validitas dengan Confirmatory Factor Analysis dapat dilihat pada tabel 1.

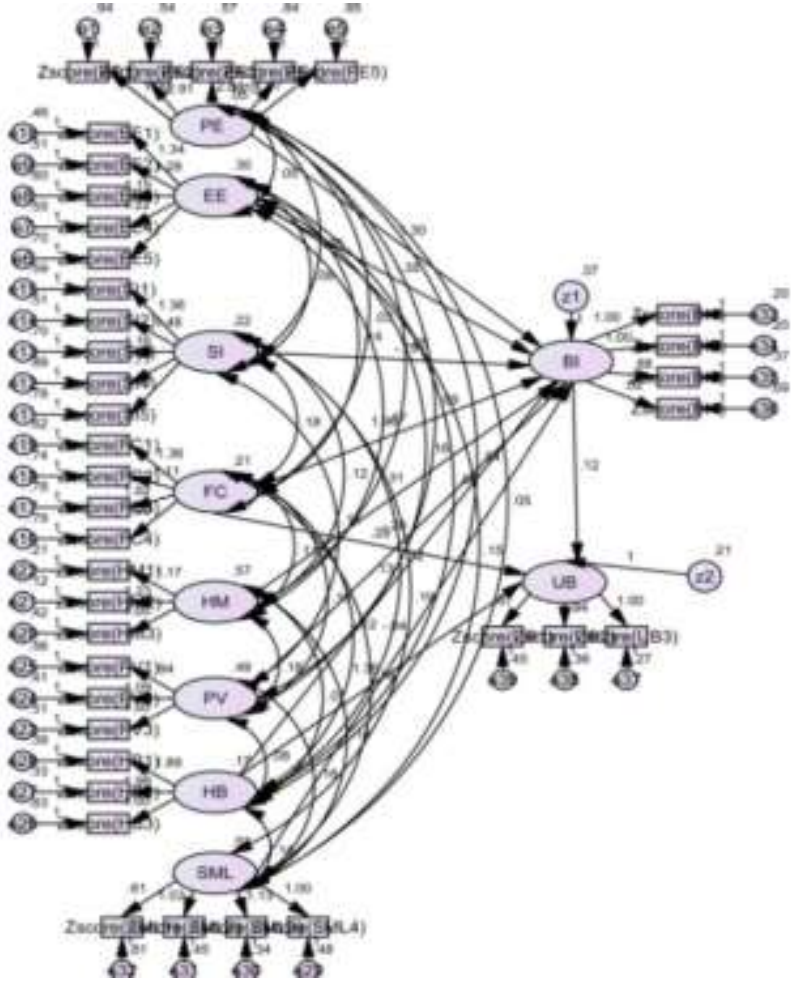

Gambar 2. Model Awal Penelitian

Tabel 1 Standardized regression weights

\begin{tabular}{|c|c|c|c|c|c|c|c|}
\hline Konstruk & $\begin{array}{l}\text { Ite } \\
\text { m }\end{array}$ & $\begin{array}{l}\text { Loadi } \\
\text { ng } \\
\text { Factor }\end{array}$ & $\begin{array}{c}\text { Keterang } \\
\text { an }\end{array}$ & Konstruk & Item & \begin{tabular}{|c|} 
Loadin \\
g \\
Factor
\end{tabular} & $\begin{array}{c}\text { Ketera } \\
\text { ngan }\end{array}$ \\
\hline \multirow{6}{*}{$\begin{array}{l}\text { Performan } \\
\text { ce } \\
\text { Expectancy }\end{array}$} & PE1 & .652 & Valid & \multirow{6}{*}{$\begin{array}{l}\text { Price } \\
\text { value }\end{array}$} & \multirow{6}{*}{$\begin{array}{l}\text { PV3 } \\
\text { PV2 } \\
\text { PV1 }\end{array}$} & \multirow{6}{*}{$\begin{array}{l}.697 \\
.772 \\
.659\end{array}$} & \multirow{6}{*}{$\begin{array}{l}\text { Valid } \\
\text { Valid } \\
\text { Valid }\end{array}$} \\
\hline & PE2 & .739 & Valid & & & & \\
\hline & PE3 & .647 & Valid & & & & \\
\hline & PE4 & .357 & Tidak & & & & \\
\hline & & & Valid & & & & \\
\hline & PE5 & .332 & $\begin{array}{l}\text { Tidak } \\
\text { Valid }\end{array}$ & & & & \\
\hline \multirow[t]{5}{*}{$\begin{array}{l}\text { Effort } \\
\text { expectancy }\end{array}$} & EE5 & .546 & Valid & \multirow[t]{5}{*}{ Habit } & \multirow{5}{*}{$\begin{array}{l}\text { HB3 } \\
\text { HB2 } \\
\text { HB1 }\end{array}$} & \multirow{5}{*}{$\begin{array}{l}.413 \\
\\
.818 \\
.783\end{array}$} & $\begin{array}{l}\text { Tidak } \\
\text { Valid }\end{array}$ \\
\hline & EE4 & .666 & Valid & & & & Valid \\
\hline & EE3 & .627 & Valid & & & & Valid \\
\hline & EE2 & 699 & Valid & & & & \\
\hline & EE1 & .736 & Valid & & & & \\
\hline \multirow[t]{5}{*}{$\begin{array}{l}\text { Social } \\
\text { influence }\end{array}$} & SI5 & .479 & $\begin{array}{l}\text { Tidak } \\
\text { Valid }\end{array}$ & \multirow{5}{*}{\begin{tabular}{|l} 
Self \\
Manageme \\
nt of \\
Learning
\end{tabular}} & \multirow{2}{*}{$\begin{array}{r}\mathrm{SM} \\
4 \\
\mathrm{SM} \\
3\end{array}$} & .719 & Valid \\
\hline & SI 4 & .337 & $\begin{array}{l}\text { Tidak } \\
\text { Valid }\end{array}$ & & & .815 & Valid \\
\hline & SI3 & .549 & Valid & & $\begin{array}{c}\text { SML } \\
2\end{array}$ & .738 & Valid \\
\hline & SI2 & .690 & Valid & & SML & .438 & $\begin{array}{l}\text { Tidak } \\
\text { Valid }\end{array}$ \\
\hline & SI1 & .632 & Valid & & & & \\
\hline \multirow{4}{*}{$\begin{array}{l}\text { Facilitatin } \\
g \\
\text { conditions }\end{array}$} & FC4 & .453 & $\begin{array}{l}\text { Tidak } \\
\text { Valid }\end{array}$ & \multirow[t]{4}{*}{$\begin{array}{l}\text { Behavioral } \\
\text { Intention }\end{array}$} & BI1 & .894 & Valid \\
\hline & FC3 & .466 & $\begin{array}{l}\text { Tidak } \\
\text { Valid }\end{array}$ & & $\mathrm{BI} 2$ & .892 & Valid \\
\hline & $\mathrm{FC} 2$ & .506 & Valid & & $\mathrm{BI} 3$ & .790 & Valid \\
\hline & $\mathrm{FC} 1$ & .619 & Valid & & BI4 & .551 & Valid \\
\hline \multirow{3}{*}{$\begin{array}{l}\text { Hedonic } \\
\text { motivation }\end{array}$} & HM3 & .758 & Valid & \multirow{3}{*}{$\begin{array}{l}\text { Use } \\
\text { Behaviour }\end{array}$} & UB3 & .852 & Valid \\
\hline & HM2 & .936 & Valid & & UB2 & .798 & Valid \\
\hline & HM1 & .888 & Valid & & UB1 & .738 & Valid \\
\hline
\end{tabular}

Factor Loading yang bernilai > 0,5 menunjukkan bahwa sebuah indikator memang bagian dari konstruk (Santoso, 2014). Dari hasil tabel diatas, maka 
indikator yang mempunyai loading factor dibawah 0,5 berarti tidak valid, karena tidak sesuai syarat convergent validity. Sehingga indikator yang harus dibuang pada model revisi adalah PE4, PE5, SI5, FC3, FC4, HB3, dan SML1.

\section{Pengujian Model}

Berdasarkan model di atas, dibuat rangkuman hasil pengujian GOF (Goodness of Fit) yang dapat dilihat pada Tabel 2 dibawah ini.

Tabel 2 Rangkuman Hasil Uji Model Keseluruhan

\begin{tabular}{|c|c|c|c|c|}
\hline $\begin{array}{c}\text { Kriteria Uji } \\
\text { Model }\end{array}$ & kala Penerimaan & Tahap-1 & Hasil & $\begin{array}{l}\text { |terpretasi } \\
\text { esesuaian }\end{array}$ \\
\cline { 4 - 5 } $\begin{array}{c}\text { Chi-square- } \\
\text { (CMin) }\end{array}$ & $\begin{array}{c}\text { Antara } \\
\text { Saturated }+ \\
\text { Independence } \\
\text { Model }\end{array}$ & 1222.616 & 583.637 & Baik (Fit) \\
\hline RMSEA & $0,05-0,08$ & .053 & .047 & Baik (Fit) \\
\hline IFI & $\begin{array}{c}0 \text { (tdk fit) s/d } \\
\text { (fit) }\end{array}$ & .880 & .942 & Baik (Fit) \\
\hline CFI & (tdk fit) s/d 1(fit) & .878 & .941 & Baik (Fit) \\
\hline
\end{tabular}

Kesimpulan yang dapat diambil secara keseluruhan adalah bahwa structural model dapat dianggap fit. Proses selanjutnya adalah melihat apakah ada hubungan yang signifikan dan erat antara variabel independen dengan variabel dependen.

\section{Estimasi Parameter}

Untuk mengetahui hubungan antar konstruk, dapat dilihat dari output estimates pada bagian regression weights. Tabel 3 berikut adalah tabel yang menyajikan regression weight model penelitian :

Tabel 3 Regression Weights: (Group number 1 Default model)

\begin{tabular}{|c|c|c|c|c|c|c|c|c|c|}
\hline & & & $\begin{array}{r}\text { Esti } \\
\text { mat } \\
\mathrm{e}\end{array}$ & $\begin{array}{l}\text { S. } \\
\text { E. }\end{array}$ & $\begin{array}{l}\text { C. } \\
\text { R. }\end{array}$ & $\mathrm{P}$ & $\begin{array}{l}\mathrm{La} \\
\text { be } \\
1\end{array}$ & & $\begin{array}{r}\text { Esti } \\
\text { mat } \\
\text { S. C. R. } P\end{array}$ \\
\hline BI & $\begin{array}{l}<- \\
-\end{array}$ & $\begin{array}{l}\mathrm{P} \\
\mathrm{E}\end{array}$ & .252 & .130 & $\begin{array}{r}1.94 \\
1\end{array}$ & $\begin{array}{r}.05 \\
2\end{array}$ & $\begin{array}{l}\text { par_2 } \\
1\end{array}$ & $\begin{array}{c}< \\
\mathrm{B}-\mathrm{H} \\
\mathrm{I}-\mathrm{B} \\
-\end{array}$ & 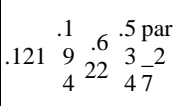 \\
\hline BI & $\begin{array}{l}<- \\
-\end{array}$ & $\begin{array}{l}\text { E } \\
\text { E }\end{array}$ & -.145 & .237 & -.612 & $\begin{array}{r}.54 \\
1\end{array}$ & $\begin{array}{l}\text { par_2 } \\
2\end{array}$ & $\begin{array}{l}<\mathrm{S} \\
\mathrm{B}-\mathrm{M} \\
\mathrm{I}-\mathrm{L} \\
-\end{array}$ & 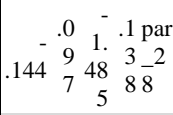 \\
\hline I & $\begin{array}{l}<- \\
-\end{array}$ & $\begin{array}{l}\text { S } \\
\mathrm{I}\end{array}$ & .055 & .147 & .371 & $\begin{array}{r}.71 \\
1\end{array}$ & $\begin{array}{l}\text { par_2 } \\
3\end{array}$ & $\begin{array}{l}< \\
\mathrm{U}-\mathrm{BI} \\
\mathrm{B}- \\
-\end{array}$ & $\begin{array}{rrrr}.0 & 2 . & .0 & \text { par } \\
.197 & 8 & 20 & 2 \\
9 & 4 & 2 \\
& 9 & 4 & 8\end{array}$ \\
\hline BI & $\begin{array}{l}<- \\
-\end{array}$ & $\begin{array}{l}\mathrm{F} \\
\mathrm{C}\end{array}$ & .869 & .611 & $\begin{array}{r}1.42 \\
2\end{array}$ & $\begin{array}{r}.15 \\
5\end{array}$ & $\begin{array}{l}\text { par_2 } \\
4\end{array}$ & $\begin{array}{c}< \\
U-F \\
B-C\end{array}$ & 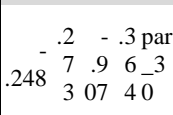 \\
\hline BI & $<-$ & $\begin{array}{l}\mathrm{H} \\
\mathrm{M}\end{array}$ & .181 & .083 & $\begin{array}{r}2.19 \\
4\end{array}$ & $\begin{array}{r}.02 \\
8\end{array}$ & $\begin{array}{l}\text { par_2 } \\
5\end{array}$ & $\begin{array}{c}< \\
\mathrm{U}-\mathrm{H} \\
\mathrm{B}-\mathrm{B} \\
-\end{array}$ & $\begin{array}{rrrr} & .1 & 6 . & * \text { par } \\
.926 & 4 & 23 & * \\
9 & 6 & * 1\end{array}$ \\
\hline BI & $\begin{array}{l}<- \\
-\end{array}$ & $\begin{array}{l}\mathrm{P} \\
\mathrm{V}\end{array}$ & .127 & .136 & .938 & $\begin{array}{r}.34 \\
8\end{array}$ & $\begin{array}{l}\text { par_2 } \\
6\end{array}$ & & \\
\hline
\end{tabular}

Dari tabel diatas, pengaruh yang signifikan ditandai dari nilai $\mathrm{P}$ yang kurang dari 0,05. Pengaruh PE dan HM signifikan terhadap BI. Sedangkan variabel EE, SI, FC, PV, HB dan SML tidak mempunyai pengaruh signifikan terhadap BI. Pengaruh BI dan HB terhadap UB signifikan, namun tidak ditemukan pengaruh yang signifikan dari FC terhadap UB karena nilai $p$ yang diatas 0,05 . Untuk menjelaskan pengaruh yang signifikan tersebut, maka bisa dilihat dari koefisien standardized. BI dipengaruhi PE dengan nilai standardized sebesar 0,195, BI dipengaruhi oleh HM dengan nilai standardized sebesar 0,68, UB dipengaruhi oleh BI dengan nilai standardized sebesar 0,195 dan UB dipengaruhi oleh HB dengan nilai standardized sebesar 8.60.

\section{E. Uji Moderasi}

Pada bagian ini akan diuji variabel moderasi umur, jenis kelamin, dan pengalaman responden pada variabel variabel penelitian yang secara signifikan memiliki hubungan dengan variabel lainnya. Hubungan antar variabel yang akan diuji yaitu moderasi usia, jenis kelamin dan pengalaman kepada pengaruh Hedonic Motivation (HM) terhadap Behavioral Intention (BI), moderasi usia, jenis kelamin dan pengalaman kepada pengaruh Habit (HB) terhadap Use Behavior (UB), serta moderasi pengalaman kepada pengaruh Behavioral Intention (BI) terhadap Use Behavior (UB).

\section{F. Uji Hipotesis}

Tabel 4 menyajikan rangkuman uji hipotesis model umum pada hasil pengujian yang dilakukan pada konstruk utama.

Tabel 4 Uji Hipotesis Model Umum

\begin{tabular}{|c|c|c|c|c|c|c|c|}
\hline & & & Hipotesis & Hasil & & Hipotesis & Hasil \\
\hline BI & $<--$ & PE & $\mathrm{H} 1$ & Diterima & $\mathrm{BI} \stackrel{-\mathrm{HB}}{<-}$ & H11 & Ditolak \\
\hline BI & $<--$ & $\mathrm{EE}$ & $\mathrm{H} 2$ & Ditolak & BI ${ }_{--}^{<-H B x A g x G d x E x p}$ & H12 & Ditolak \\
\hline BI & $<--$ & SI & $\mathrm{H} 3$ & Ditolak & $\mathrm{UB}_{--}^{<-} \mathrm{HB}$ & $\mathrm{H} 13$ & Diterima \\
\hline BI & $<--$ & FC & $\mathrm{H} 4$ & Ditolak & UB ${ }_{--}^{<-}$HBxAgxGdxExp & H14 & Ditolak \\
\hline UB & $<--$ & FC & H5 & Ditolak & BI $<-$ SML & H15 & Ditolak \\
\hline UB & $<--$ & FCxAgxGdxExp & H6 & Ditolak & BI $\stackrel{-}{-}$ SMLxAg & H16 & Ditolak \\
\hline BI & $<--$ & HM & $\mathrm{H} 7$ & Diterima & BI $\stackrel{--}{<-}$ SMLxGd & H17 & Ditolak \\
\hline BI & $<--$ & HMxAgxGdxExp & H8 & Ditolak & $\mathrm{UB}_{--}^{<-} \mathrm{BI}$ & H18 & Diterima \\
\hline BI & $<--$ & PV & H9 & Ditolak & UB ${ }_{--}^{<-}$BIxExp & H19 & Ditolak \\
\hline BI & $<--$ & PVxAgxGdxExp & H10 & Ditolak & & & \\
\hline
\end{tabular}


G. Model Akhir Penelitian

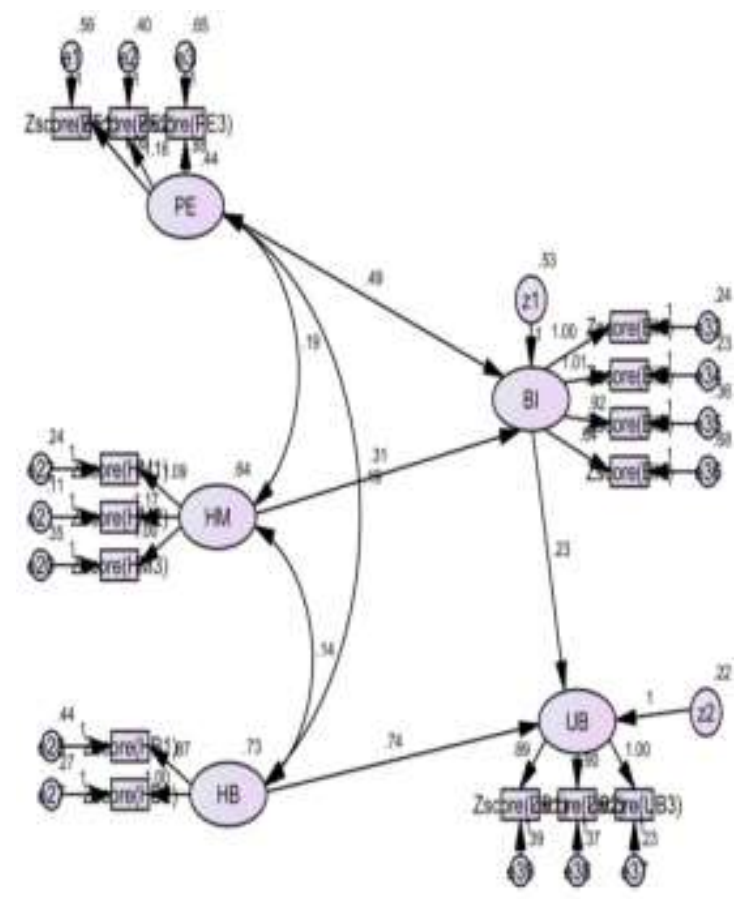

Gambar 3. Model Akhir Penelitian

Tabel 5 berikut adalah tabel yang menyajikan regression weight model akhir penelitian berdasarkan variabel utama, seluruh variabel model akhir yaitu variabel PE dan HM mempengaruhi secara signifikan terhadap BI, dan variabel HB mempengaruhi secara signifikan terhadap UB.

Tabel 5 Regression Weights Model Akhir Penelitian

\begin{tabular}{|c|c|c|c|c|c|c|c|c|c|}
\hline & & & $\begin{array}{l}\text { Esti } \\
\text { mate }\end{array}$ & $\begin{array}{l}\text { S. } \\
\text { E. }\end{array}$ & $\begin{array}{l}\text { C. } \\
\text { R. }\end{array}$ & $P$ & $\begin{array}{l}\text { Lab } \\
\text { el }\end{array}$ & & $\begin{array}{c}\text { Esti S. C. } \\
\text { mate E. R. } \mathrm{P} \text { el }\end{array}$ \\
\hline $\begin{array}{l}\text { B } \\
\text { I }\end{array}$ & & $\begin{array}{l}P \\
E\end{array}$ & 489 & $\begin{array}{r}.1 \\
08\end{array}$ & $\begin{array}{r}4.5 \\
31\end{array}$ & $\begin{array}{r}* \\
* \\
*\end{array}$ & $\begin{array}{l}\text { par } \\
-11\end{array}$ & $\begin{array}{l}< \\
U-B \\
B-\text { I }\end{array}$ & $.233 .04 .1{ }^{*} \mathrm{*ar}$ \\
\hline $\begin{array}{l}\text { B } \\
\text { I }\end{array}$ & & $\begin{array}{l}\mathrm{H} \\
\mathrm{M}\end{array}$ & .314 & $\begin{array}{r}.0 \\
74\end{array}$ & $\begin{array}{r}4.2 \\
70\end{array}$ & $\begin{array}{r}* \\
* \\
*\end{array}$ & $\begin{array}{l}\text { par } \\
-12\end{array}$ & $\begin{array}{l}<- \\
\mathrm{U}-\mathrm{H} \\
\mathrm{B}-\mathrm{B} \\
-\end{array}$ & $.742 .09 .6{ }^{*} \begin{array}{rrr}* \\
77 & 25 & *-14\end{array}$ \\
\hline
\end{tabular}

\section{KESIMPULAN}

Faktor - faktor yang mempengaruhi penerimaan dan penggunaan Media Pembelajaran Augmented Reality (AR) pada SMP dan SMA Mutiara Bunda Performance Expectancy, Hedonic Motivation, dan Habit. Besar pengaruh masing-masing faktor dalam penerimaan dan penggunaan media pembelajaran $\mathrm{AR}$ adalah Performance Expectancy (PE) terhadap memberi pengaruh positif sebesar $37,2 \%$ terhadap Behavioral Intention (BI),
Hedonic Motivation (HM) terhadap memberi pengaruh positif sebesar 28,9\% terhadap Behavioral Intention (BI), Behavioral Intention (BI) memberi pengaruh positif sebesar $24.2 \%$ terhadap Use Behaviour (UB), Habit (HB) memberi pengaruh positif sebesar $75.5 \%$ terhadap Use Behaviour (UB).

Beberapa saran yang dapat digunakan untuk penelitian selanjutnya antara lain diperlukan variabel moderasi kepada responden pada berbagai tingkat sehingga akan menghasilkan estimasi yang lebih baik. Diharapkan dalam penelitian selanjutnya dapat menambahkan konstruk yang lain yang mendukung sehingga hasil yang lebih tepat dapat dicapai.

\section{REFERENSI}

[1] Venkatesh, V., Thong James,Y, L.,\& Xu, Xin. 2012. Consumer Acceptance And Use of Information Technology : Extending The Unified Theory of Acceptance And Use of Technology. Vol. 36, No. 1.

[2] Souza-Concilio, Ilana de A., Beatriz A. Pacheco. 2013. The Development of Augmented Reality Systems in Informatics Higher Education. Brazil : Computers and Informatics Faculty, Mackenzie Presbyterian University.

[3] Sugiyono, 1997. Metode Penelitian Administrasi. Bandung. Alfabeta. 